\title{
COTARD SYNDROME AND THE ROLE OF THE SEQUELAE OF TRAUMATIC BRAIN INJURY - A CASE REPORT

\section{BACKGROUND}

Cotard syndrome is a rare neuropsychiatric condition in which the patient believes he or she is dead. ${ }^{1}$ It may also manifest itself with nihilistic delusions concerning body parts. Several studies have established a strong relationship with multiple neurological conditions, including the association with organic lesions and atrophy of the non-dominant temporo-parietal cortex. ${ }^{1,2,3}$

The author reviews the literature on Cotard syndrome in relation to the presence of brain lesions, addressing a clinical case.

\section{METHODS}

A clinical description of the case report was carried out, with a review of the pertinent scientific literature.

\section{CASE REPORT}

J., a 62-year-old male, is admitted to our inpatient psychiatric unit due to episodes of aggression and a delirious condition compatible with Cotard's syndrome, with no mood changes and with at least one year of evolution. From the longitudinal evaluation carried out, there is a history of traumatic brain injury that occurred about 20 years ago with consequent personality changes.
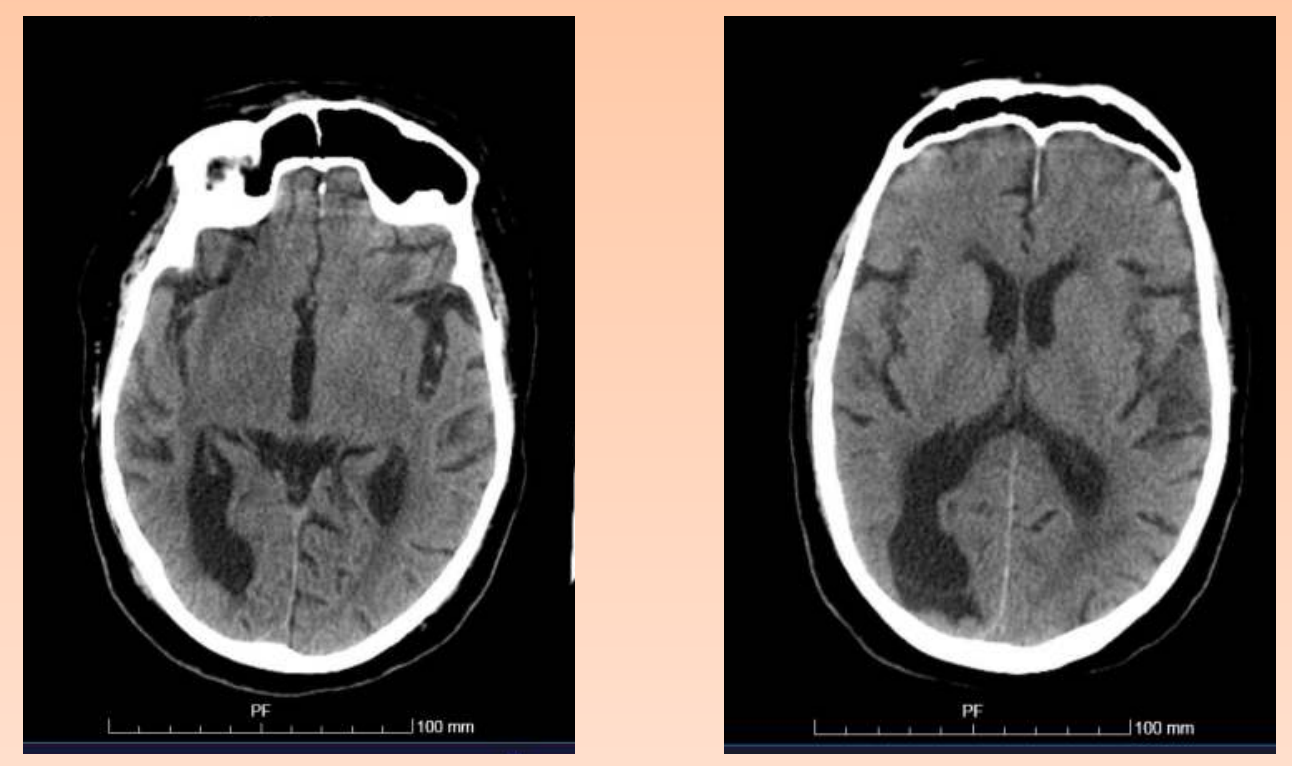

\section{Head CT revealed an extensive area of right upper and middle parietal cortico- subcortical encephalomalacia}

After three weeks of treatment with risperidone $4 \mathrm{mg} / \mathrm{d}$, there was an improvement in patient behavior and delusional ideation became less intense, however it was not possible to achieve total remission of delusional symptomatology.

\section{CONCLUSIONS}

This case report highlights the relationship between the location of brain lesions and certain specific syndromes and the possibility of manifesting at different times from the one in which traumatic brain injury occurred. ${ }^{1}$

\section{REFERENCES}

${ }^{1}$ Sahoo A, B.S., Josephs KA. A Neuropsychiatric Analysis of the Cotard Delusion. J Neuropsychiatry Clin Neurosci. 2018;30:58-65

${ }^{2}$ Kudlur SNC, George S, Jaimon M. An overview of the neurological correlates of Cotard syndrome. Eur J Psychiat. 2007;21,(2):99-116.

${ }^{3}$ Morgado P, Ribeiro R, Cerqueira JJ. Cotard Syndrome without Depressive Symptoms in a Schizophrenic Patient. Case Rep Psychiatry. 2015;2015:643191.

${ }^{4}$ Grover S, Aneja J, Mahajan S, Varma S. Cotard's syndrome: Two case reports and a brief review of literature. J Neurosci Rural Pract. 2014;5(Suppl 1):S59S62. 